\title{
EDITORIAL
}

For reprint orders, please contact: reprints@futuremedicine.com

\section{The Medicare loophole: cost-sharing for screening colonoscopy}
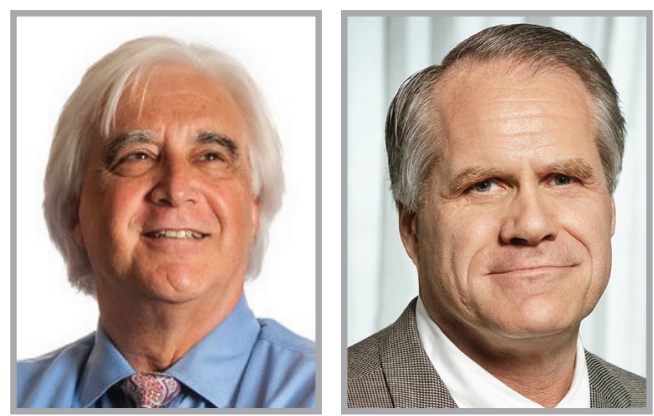

\author{
"Over 300 health-related \\ organizations, led by the \\ National Colorectal Cancer \\ Roundtable, have committed \\ to increasing the nation's \\ colorectal cancer screening \\ rate to $80 \%$ of eligible \\ individuals by the year 2018.”
}

Franklin G Berger ${ }^{*, 1}$ \& Christopher W Hansen²

Colorectal cancer (CRC) is the second most common cause of death from cancer in men and women in the USA. The American Cancer Society estimates that more than 132,000 people will be diagnosed with CRC, and almost 50,000 will die from the disease, in the USA in 2015 [1]. Treatment costs can be very high, especially for advanced forms of CRC. Total expenditures of about US $\$ 13.8$ billion for treatment of CRC each year have been estimated, with Medicare bearing more than one half of these costs [2]. Indeed, treating a single advanced case of CRC may exceed US $\$ 300,000$ per year [3]. Yet, the morbidity and costs due to CRC are largely avoidable. It is well documented that regular screening can identify CRC at early stages, when it is easiest and least expensive to treat, and when the possibility of long-term survival is the greatest. Additionally, screening can actually prevent the development of CRC through the detection and removal of precancerous polyps (abnormal growths in the lining of the colon), eliminating the possibility that they may progress into cancer. Recently, a systematic review of 39 screening tests for 19 diseases revealed that only four tests, two of which were for CRC, exhibited a significant diseasespecific mortality benefit [4]. It is therefore clear that preventive screening is a highly efficacious strategy to reducing the incidence and mortality of CRC.

Over 300 health-related organizations, led by the National Colorectal Cancer Roundtable, have committed to increasing the nation's CRC screening rate to $80 \%$ of eligible individuals by the year 2018. To achieve this goal, barriers that prevent Americans from getting screened must be removed. The American Cancer Society, the US Preventive Services Task Force (USPSTF) and other expert medical and scientific panels have issued evidence-based recommendations for CRC screening [5]. Even with expanded access to insurance coverage under the Affordable Care Act (ACA), too many Americans are still not getting screened for CRC. Reasons for this vary. Although many factors, including awareness, physician recommendations, access to

\section{Colorectal Cancer}

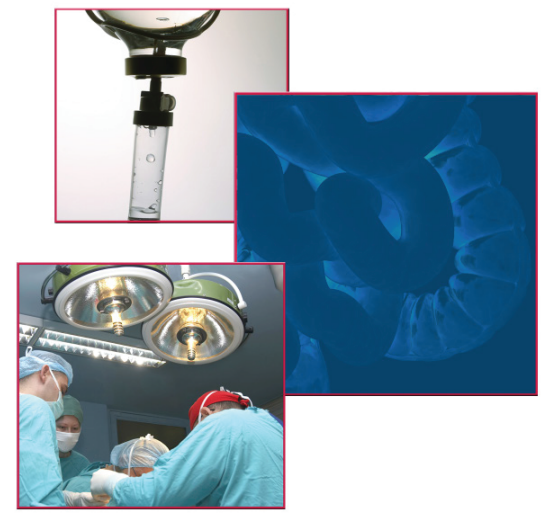

\section{KEYWORDS}

- colorectal cancer • Medicare

- screening

\section{“It is well documented that regular screening can identify colorectal cancer at early stages..."}


"Under Medicare, if a polyp is found and removed during a routine colonoscopy, the procedure is coded as diagnostic, and a 20\% co-pay is charged." providers, among others contribute to the decision to undergo CRC screening, affordability is a significant deterrent [6].

Through programs that utilize evidencebased health promotion strategies to encourage and promote screening, CRC incidence rates have dropped $30 \%$ in the USA among adults 50 years and older over the last decade [7]. Recent implementation of the Affordable Care Act (ACA) is likely to further reduce these rates. Yet, many Americans do not engage in CRC screening as recommended, and one in three adults between the ages of 50 and 75 years are not up to date with screening recommendations [8], even though general awareness of CRC screening is high [9].

Despite Medicare coverage, only $63.7 \%$ of adults aged 65 years and over were up to date with regard to CRC screening, as of 2010 [7]. CRC takes a significant toll on the Medicare population, both in terms of lives affected and the staggering treatment costs. Approximately $60 \%$ of cases and $70 \%$ of deaths due to CRC occur in those aged 65 years and older. Of the 137,000 people who will be diagnosed with CRC in 2015, nearly two-thirds fall within the Medicare population [10].

With the passage of the ACA, an estimated 54 million Americans are able to receive expanded coverage of preventive services [11]. The ACA eliminated all co-insurance requirements for routine screening tests that receive an 'A' or 'B' rating from the USPSTF. For individuals between ages 50 and 75 years, colonoscopy has an A-rating, meaning that screening colonoscopies must be provided without costsharing because of its proven public health benefits. In 2013, the US Department of Health and Human Services mandated that for those in qualified health plans under the ACA, no cost-sharing would occur for a screening colonoscopy, even if one or more polyps were detected and removed during the procedure. However, no such mandate has been made for Medicare beneficiaries. Under Medicare, if a polyp is found and removed during a routine colonoscopy, the procedure is coded as diagnostic, and a $20 \%$ co-pay is charged. This translates into out-of-pocket costs of as much as US $\$ 300$ or more per patient, which often comes unexpectedly after the procedure has occurred. As mentioned above, though Medicare covers screening colonoscopy without cost sharing if there is no polypectomy, greater than a third of adults aged 65 years and over were not current with screening recommendations in 2010 [7].

For those seniors who rely on Medicare for their health coverage, even a small co-pay can be a serious disincentive to getting screened. Extensive research has demonstrated that individuals - including the insured - are less likely to seek health services when they have to pay out-of-pocket costs [11-14]. Most medical experts understand that screening colonoscopies are intended to find a polyp and remove it before it turns into cancer. As such, the identification and removal of a polyp is considered to be part of the screening protocol, and should be covered as such by insurance providers, including Medicare. Current Medicare policy is, therefore, a loophole that requires correction.

Legislation currently in Congress addresses the Medicare co-pay issue, and is critical to reaching the goal of screening $80 \%$ of eligible individuals for CRC by 2018. The Removing Barriers to Colorectal Cancer Screening Act of 2015 (S. 624/H.R. 1220), introduced by Reps Charlie Dent (R-PA) and Donald Payne Jr (D-NJ) and Sens Sherrod Brown (D-OH) and Roger Wicker (R-MS), amends the Social Security Act to waive co-insurance for CRC screening for Medicare beneficiairies regardless of whether or not a precancerous lesion is removed during the procedure. These bipartisan bills provide a reasonable and intelligent fix for the loophole in Medicare coverage of screening colonoscopies, thereby placing Medicare beneficiaries on par with those covered by private insurance, including that under the ACA. Passage of these bills represents a crucial step in the effort to ensure that unexpected costs do not determine who does and does not receive potentially lifesaving cancer screenings. We urge the US Congress to pass these bills to help save lives, and reduce the pain, suffering and healthcare costs associated with CRC.

\section{Financial \& competing interests disclosure}

The authors have no relevant affiliations or financial involvement with any organization or entity with a financial interest in or financial conflict with the subject matter or materials discussed in the manuscript. This includes employment, consultancies, honoraria, stock ownership or options, expert testimony, grants or patents received or pending, or royalties.

No writing assistance was utilized in the production of this manuscript. 


\section{References}

1 Cancer Facts and Figures, 2015. American Cancer Society, Atlanta, GA, USA. www.cancer.org/acs/groups

2 Mariotto AB, Yabroff KR, Shao Y, Feuer EJ, Brown ML. Projections of the Cost of Cancer Care in the United States: 2010-2020. J. Natl. Cancer Inst. 103(2), 117-128 (2011).

3 Schrag D. The price tag on progress chemotherapy for CRC. N. Engl. J. Med. 351(4), 317-319 (2004).

4 Saquib N, Saquib J, Ioannidia JPA. Does screening for disease save lives in asymptomatic adults? Systematic review of meta-analyses and randomized trials. Int. J. Epidemiol. 44, 264-277 (2015)

5 US Preventive Services Task Force. Screening for colorectal cancer: US Preventive Services Task Force recommendation statement. Ann. Intern. Med. 149, 627-637 (2008).
62014 American Cancer Society Market Research.

http://nccrt.org/wp-content/uploads

7 Colorectal Cancer Facts and Figures 2014-2016. American Cancer Society, Atlanta, GA, USA.

www.cancer.org/acs/groups

8 CDC. Prevalence of CRC screening among adults - Behavioral Risk Factor Surveillance System, United States, 2012. MMWR 2013, Vol. 62.

www.cdc.gov/mmwr/preview

9 Brandt HM, Dolinger HR, Sharpe PA, Hardin JW, Berger FG. Relationship of colorectal cancer awareness and knowledge with colorectal cancer screening. Colorectal Cancer 1(5), 383-396 (2012).

10 Sommers BD, Wilson L. Fifty-four million additional Americans are receiving preventive services without cost-sharing under the affordable care act: issue brief, office of the assistant secretary for planning and evaluation (2012).

http://aspe.hhs.gov/pdf-report

11 Solanki G, Schauffler HH, Miller LS. The direct and indirect effects of cost-sharing on the use of preventive services. Health Serv. Res. 34, 1331-1350 (2000).

12 Wharam JF, Graves AJ, Landon BE, Zhang F, Soumerai SB, Ross-Degnan D. Two-year trends in colorectal cancer screening after switch to a high-deductible health plan. Med. Care 49, 865-871 (2011).

13 Trivedi AN, Rakowski W, Ayanian JZ. Effect of cost sharing on screening mammography in Medicare health plans. N. Engl. J. Med. 358, 375-383 (2008).

14 Manning WG, Newhouse JP, Duan N et al. Health insurance and the demand for medical care: evidence from a randomized experiment. (1988).

www.rand.org/content/dam/rand 